\title{
Assessment of the Cost of the Mediterranean Diet in a Low-Income Region: Adherence and Relationship with Available Incomes
}

\author{
Alessia Rubini ${ }^{1,2}$, Cristina Vilaplana-Prieto ${ }^{3}$, Marta Flor-Alemany ${ }^{4}$, Lorena Yeguas-Rosa ${ }^{2}$, \\ Miriam Hernández-González 1,2, Francisco Javier Félix-García ${ }^{5}$, Francisco Javier Félix-Redondo ${ }^{2,6}$ and \\ Daniel Fernández-Bergés ${ }^{1,2^{*}}$ (1)
}

\begin{abstract}
Background: The Mediterranean Diet (MD) is recognized as heart-healthy, but the economic cost associated with this type of diet has scarcely been studied.

The objective of the present study is to explore the cost and adherence of a low-income region population to the MD and its relationship with income.

Methods: A population-based study was carried out on 2,833 subjects between 25 and 79 years of age, 54\% women, selected at random from the municipalities of Vegas Altas, La Siberia and La Serena in the province of Badajoz,

Extremadura (Spain).

Average monthly cost of each product included in the MD was computed and related to adherence to the MD using the Panagiotakos Index and average disposable income.

Results: The monthly median cost was 203.6€ (IQR: 154.04-265.37). Food-related expenditure was higher for men $(p<0.001)$, age cohort between 45 and 54 years $(p<0.013)$ and those living in urban areas $(p<0.001)$. A positive correlation between food-related expenditure and the MD adherence was found. Monthly median cost represents $15 \%$ of average disposable income, ranging between $11 \%$ for the group with low MD adherence and $17 \%$ for the group with high MD adherence.

Conclusions: The monthly cost of the MD was positively correlated with the degree of adherence to this dietary pattern. Given that the estimated monthly cost is similar to that of other Spanish regions with a higher income level, the economic effort required to be able to afford the Mediterranean diet is higher. This may represent a barrier to access, which should be analyzed in detail by public decision-makers.
\end{abstract}

Keywords: Mediterranean diet, Food expenditure, Adherence, Monetary cost

*Correspondence: daniel.fernandezb@salud-juntaex.es

${ }^{1}$ Research Unit of Don Benito-Villanueva de la Serena Health Area, Calle

Sierra Nevada, 10, 06700 Villanueva de la Serena, Spain

Full list of author information is available at the end of the article

\section{Introduction and Objectives}

Cardiovascular disease (CVD) is the primary cause of death in developed countries. Leading a healthy lifestyle (a proper diet, suitable levels of physical activity, and the reduction of toxic habits) is essential to prevent it $[1,2]$. The Mediterranean Diet (MD) is widely recognised as being cardiovascular-healthy [3-5] although few studies have been carried out on the associated cost of this type 
of food and is rarely used as an argument in the debate on public monitoring by health policy makers.

The MD focuses on the consumption of olive oil as the main source of fat; a high consumption of fruit, vegetables, nuts and dried fruit, and whole grains; a moderate consumption of wine, meat, fish, eggs, and dairy products; and a low consumption of red meat, processed foods, and sugary drinks [1]. Several studies have found that populations with a high adherence to MD patterns show a lower rate of CVD [3-6]. In 2010, UNESCO declared MD an Intangible Cultural Heritage of Humanity and the World Health Organisation classified it as a diet that protects against CVD [7].

The cost of food plays an important role in determining decisions related to the purchase and food consumption [8]. The first evidence on the monetary cost of food products was conducted in the late 1990s [9]. Since then, several studies have reported on the economics of dietary patterns [10-15]. It has been pointed out that healthy diets cost more than unhealthy diets [10]. A recent review showed that a diet rich in fruits, vegetables and nuts was, on average, $\$ 1.5$ more expensive per day than a diet of processed foods, meat and refined grains [11].

Following a cheaper diet can lead to health problems for consumers due to reduced nutritional quality. Therefore, dietary cost can be a barrier to the adoption of a healthy diet, particularly among people with lower socioeconomic status $[16,17]$.

This socioeconomic gradient in the quality of their diet is therefore likely to contribute to the health disparity among different socioeconomic groups [12], ultimately leading to an increase in overall societal costs $[13,14]$. Estimates for Spain have also confirmed the higher cost associated with higher adherence to MD, but remarkable differences can be found between studies, with the cost of high adherence being between $18 \%$ and $28 \%$ higher than that of low adherence $[15,18]$. However, none of these studies have related the cost of MD to disposable income, which is very relevant if we want to assess the affordability of MD for families.

Our objective was to study the cost and level of adherence to the MD of the population of a low-income region, as well as its relationship with the level of disposable income.

\section{Material and Methods Study sample}

A cohort study consisting of a population sample of 2,833 subjects selected randomly as representative of between 25 and 79 years of age of the municipalities of Vegas Altas, La Siberia, and La Serena in the province of Badajoz (Extremadura), which amounts to 75,455 inhabitants.
The region of Extremadura was chosen for several reasons. Firstly, because it has one of the highest rates of morbidity and mortality from cardiovascular disease compared to other Spanish regions [19]. Secondly, because it is the Spanish region with the lowest income level (25.82\% below the average income) [20].

The methodology used has previously been validated and published [21]. Briefly, the cohort is a populationbased study representative of a health area in Extremadura. This was obtained by the simple random method from a database, of the public health service with universal coverage $(99.4 \%)$. The sample size was calculated to be necessary to estimate the prevalence of different characteristics of the population, with a maximum degree of uncertainty and an accuracy of $2 \%$, resulting 2400 subjects. The inclusion criteria were people between 25 and 79 years old, who lived in one of the 16 populations of more than 2000 inhabitants of the health area, in 2007. Pregnant women, institutionalized subjects, those with serious or terminal illness, and those who were not resident in the afore mentioned area were excluded. The socio demographic profile is described in Table 1.

\section{Nutritional register}

The dietary assessment of the participants was carried out using of a previously validated semi-quantitative questionnaire on the frequency of food consumption with 157 food variables and 7 variables related to the consumption of alcoholic drinks [22] (see Table A1 of the Appendix). For all of them, intake was assessed on a

Table 1 Socio demographic profile of the Hermex study

\begin{tabular}{lllll}
\hline & Global & Male & Female & p-value \\
\hline N (\%) & $2,833(100 \%)$ & $1,317(46.5 \%)$ & $1,516(53.5 \%)$ & \\
Age (years), Mean & $51.2(14.7)$ & $51.3(14.6)$ & $51.1(14.9)$ & 0,734 \\
(SD) & & & & \\
Age, distribution by decades & & & \\
$\quad 25-34$ & $407(14.4 \%)$ & $178(13.5 \%)$ & $229(15.1 \%)$ & \\
$\quad 35-44$ & $671(23.7 \%)$ & $309(23.5 \%)$ & $362(23.9 \%)$ & \\
$45-54$ & $616(21.7 \%)$ & $298(22.6 \%)$ & $318(21.0 \%)$ & 0.404 \\
$55-64$ & $502(17.7 \%)$ & $240(18.2 \%)$ & $262(17.3 \%)$ & \\
$\quad 65-74$ & $418(14.8 \%)$ & $201(15.3 \%)$ & $217(14.3 \%)$ & \\
$\quad 75-79$ & $219(7.7 \%)$ & $91(6.9 \%)$ & $128(8.4 \%)$ & \\
Rural origin & $1,445(51.0 \%)$ & $688(52.2 \%)$ & $757(49.9 \%)$ & 0.221 \\
Level of education & & & & \\
Illiterate & $358(12.7 \%)$ & $138(10.5 \%)$ & $220(14.6 \%)$ & \\
Primary studies & $1,526(54.2 \%)$ & $743(56.8 \%)$ & $783(51.9 \%)$ & $<0.001$ \\
Secondary studies & $586(20.8 \%)$ & $288(22.0 \%)$ & $298(19.7 \%)$ & \\
Higher degree & $348(12.3 \%)$ & $140(10.7 \%)$ & $208(13.8 \%)$ & \\
\hline
\end{tabular}

Source: Félix-Redondo FJ, Fernández-Bergés D, Pérez JF et al. Prevalencia, detección, tratamiento y grado de control de los factores de riesgo cardiovascular en la población de Extremadura. Estudio HERMEX. Aten Primaria. 2011;43(8) 426-434 
scale ranging between 0 and 9 , in which 0 corresponds to "never or less than once a month" and 9 to " 6 or more times a day".

\section{Cost assessment}

In order to compute the daily (or monthly) cost of the diet, we have followed three steps. Firstly, records on consumption frequencies were converted to grams or millilitres (see note to Table A1 of the Appendix). Secondly, taking the year 2019 as a baseline, the average price was obtained for each category, using price comparators of supermarkets located in the same geographical area as the study population, i.e. Carrefour, Mercadona, and Día (see Table A2 of the Appendix for details of the number of references used in each category and the average, minimum, and maximum prices). Thirdly, the total daily (or monthly) cost for each participant was obtained as the product of the daily (or monthly) quantity consumed by the price of the respective category.

The costs of the products are expressed indicating the mean and standard deviation (SD) when they follow a Gaussian distribution, and with the median and interquartile range (IQR) when the distribution is not normal.

\section{Statistical analysis}

Once the total cost had been calculated, population was segmented by sex, age, educational level and place of residence. A lineal regression analysis was performed using monthly cost as dependent variable and segmentation variables as regressors ( $\mathrm{p}$-values are shown by means of the 3000 bootstrap samples).

Finally, the Panagiotakos Adherence Index (PAI) was used to obtain the correlation between monthly cost and adherence to MD. PAI is a score based on 11 components (non-refined cereals, vegetables, fruit, potatoes, legumes, olive oil, fish, red meat, poultry, full fat dairy products and alcohol). Each component is assigned a score from 0 to 5 , depending on intake. Products that are not typical of MD (e.g. red meat) are evaluated on an upside down ladder. The total score ranges from 0 to 55 points, where a higher score leads to a higher level of adherence [23].

Results of PAI were divided distinguishing 3 adherence groups based on the resulting score: low adherence to MD (PAI< 29.99), medium (PAI between 30 and 33.99) and high $(\mathrm{PAI}>34)$. A recent systematic review ranks this index as one of those that provides the most outstanding amount of information and for that reason, it has been selected to assess adherence to MD [24].

The different cost levels associated to the different degrees of adherence to MD were compared using the Pearson's correlation index as a measure of lineal association and the Kruskal-Wallis test as a non-parametric tool to study the significance of the differences between the levels of adherence. A value of $\mathrm{p}<0.05$ was considered significant.

In order to compare monthly cost with income, data from the Statistical System of Extremadura [25] were used. The average disposable income (monthly and annual) was obtained as a weighted average among the different municipalities of the of Vegas Alta, La Serena and La Siberia.

Microsoft Excel and statistical package IBM SPSS 21 were used as computer support.

\section{Results}

Table 2 shows that the median of the monthly food cost (MFC) was 203.63€ (IQR: 154.04-265.37). With a significance level $(\mathrm{p}<0.001)$, MFC of men was $13.43 \%$ higher for men (216.91€; IQR: 167.64-280.13) than for women (191.22€ (IQR: 145.07-248).

The MFC median by age cohorts $(\mathrm{p}<0.013)$ has an inverted U-shape with a maximum attained for the cohort aged 45-54 years (212.11€; IQR 155.47-274.63). The minimum cost corresponds to the cohort of 75-79 years (179€; IQR 130.21-224.99), i.e. 15.61\% less than the cohort aged 45-54 years old.

As for the place of residence, the cost in rural areas was 188.26€ (IQR: $147.83-232.93$ ) as compared to $223.52 €$ (IQR; $166.06-296.91)$ in urban areas, i.e. 14,64\% less among residents in rural areas $(\mathrm{p}<0.001)$.

No significant differences $(p<0.701)$ were found between different levels of education and the MFC (see Fig. 1).

As for adherence to MD, the higher adherence, the higher MFC. According to PAI, MFC associated with high adherence was $229.38 €$, that is, $34.50 \%$ and $49.37 \%$ higher as compared to medium and low adherence, respectively. The positive values of the Pearson coefficient and the significant differences between the different adherence groups according to the Kruskal-Wallis test support these results. (Table 3).

Table 4 shows the MFC and the PAI as percentages of various income indicators. The median of the MFC represents $22.60 \%$ of the official minimum wage, $37.81 \%$ of the IPREM (indicator used to calculate the minimum guaranteed income by social benefits), $44.02 \%$ of the minimum living income support, and $51.88 \%$ of the noncontributory pension. Even for low adherence to MD, monthly cost is close to $30 \%$ of the IPREM and above this threshold for minimum living income support and noncontributory pensions.

Table 4 exhibits the MFC and PAI with respect to the mean disposable income for Spain, Extremadura, Badajoz and in the municipalities of Vegas Altas, La Siberia and La Serena. In the aforementioned municipalities, the MFC amounts to $14.98 \%$ of the average disposable 
Table 2 Descriptive statistics of costs categorized by sex, age, level of education and place of residence.

\begin{tabular}{|c|c|c|c|c|c|c|c|}
\hline \multirow{2}{*}{$\begin{array}{l}\text { Sex* } \\
N\end{array}$} & & \multirow{2}{*}{$\begin{array}{l}\text { Total } \\
2.833\end{array}$} & \multirow{2}{*}{$\begin{array}{c}\text { Male } \\
1.317\end{array}$} & \multicolumn{4}{|l|}{ Female } \\
\hline & & & & 1.516 & & & \\
\hline & $\%$ & $100 \%$ & $46,49 \%$ & $53,51 \%$ & & & \\
\hline Median & & 203,63 & 216,91 & 191,22 & & & \\
\hline \multirow[t]{2}{*}{ Percentiles } & 25 & 154,04 & 167,64 & 145,07 & & & \\
\hline & 75 & 265,37 & 280,13 & 248,00 & & & \\
\hline Age $* *$ & & $25-34$ years & $35-44$ years & $45-54$ years & $55-64$ years & $65-74$ years & 75-79 years \\
\hline \multirow[t]{2}{*}{$\mathrm{N}$} & & 407 & 671 & 616 & 502 & 418 & 219 \\
\hline & $\%$ & $14,37 \%$ & $23,69 \%$ & $21,74 \%$ & $17,72 \%$ & $14,75 \%$ & $7,73 \%$ \\
\hline Median & & 203,27 & 206,63 & 212,11 & 210,76 & 193,95 & 179,00 \\
\hline \multirow[t]{2}{*}{ Percentiles } & 25 & 152,48 & 158,10 & 155,47 & 163,44 & 149,46 & 130,21 \\
\hline & 75 & 266,73 & 270,79 & 274,63 & 267,36 & 246,18 & 224,99 \\
\hline Place of Residence *** & & Rural & Urban & & & & \\
\hline \multirow[t]{2}{*}{ N } & & 1.445 & 1.388 & & & & \\
\hline & $\%$ & $51,36 \%$ & $48,64 \%$ & & & & \\
\hline Median & & 188,26 & 223,52 & & & & \\
\hline \multirow[t]{2}{*}{ Percentiles } & 25 & 147,83 & 166,06 & & & & \\
\hline & 75 & 232,93 & 296,91 & & & & \\
\hline Level of education **** & & Illiterate & Primary studies & Secondary studies & $\begin{array}{l}\text { Higher degree, uni- } \\
\text { versity o similar }\end{array}$ & & \\
\hline \multirow[t]{2}{*}{ N } & & 358 & 1.541 & 586 & 348 & & \\
\hline & $\%$ & $12,64 \%$ & $54,39 \%$ & $20,68 \%$ & $12,29 \%$ & & \\
\hline Median & & 177,70 & 208,18 & 206,57 & 205,70 & & \\
\hline \multirow[t]{2}{*}{ Percentiles } & 25 & 131,84 & 156,83 & 157,75 & 161,12 & & \\
\hline & 75 & 223,73 & 269,78 & 271,28 & 269,06 & & \\
\hline
\end{tabular}

Own elaboration with data from HERMEX study. ${ }^{*} p<0,001 ;{ }^{* *} p<0,013 ;{ }^{* * *} p<0,001 ;{ }^{* * * *} p<0,701$

income, ranging between $11.31 \%$ for the group with low adherence and $16.90 \%$ for the group with high adherence. These values are similar for Badajoz and Extremadura. At the country level, MFC represents $10.78 \%$ of the national mean disposable income, ranging from $8.14 \%$ for low adherence group and $12.16 \%$ for high adherence group.

\section{Discussion}

The main result is that the average monthly food cost (MFC) shows a positive correlation with level of adherence to MD and amounts to 203.63€. In second place, we highlight that MFC is higher for men, the cohort aged between 45 and 54 years and those living in urban areas.

This study is the first to relate the cost, level of adherence, and level of income to the MD in the population of Extremadura, which is that of the lowest per capita income in Spain [20].

\section{Costs, economic resources, and adherence to the MD}

Despite the significant income differences among Spanish regions, such as Navarra, Cataluña, and Extremadura [20], our estimated MFC is coherent with previous research by Fresán et al. [26] and Schröder et al [18].
The former study relied on university student data aged between 27 and 45 years old living in Catalonia (whose average income is $14.40 \%$ above the Spanish mean [20]) found that the estimated MFC was $226 €$. In the study by Schröder et al [18], which focused on the aged cohort between 25 and 74 years of age living in Navarra (where average income is $18.81 \%$ above the Spanish mean [20]), the MFC was $220 €$. Considering that the average levels of income of the regions are very different, it is clear that the economic effort will differ in accordance with the income of each region.

The relationship between economic resources and the level of adherence to a healthy diet is a factor which is not usually considered in daily welfare clinical practice. Various studies $[10,15,16]$ have described a higher level of adherence to the healthy pattern of the MD in the population with higher income. Schröder et al. [18] observed that the MFC associated with high adherence was $237.60 €$, while that associated with low adherence was $202.20 €$.

On the other side, López et al. [27] stressed that a good adherence to the MD involved a higher cost than good adherence to other dietary patterns. In their study they described the eating behaviour of 11,195 participants and 


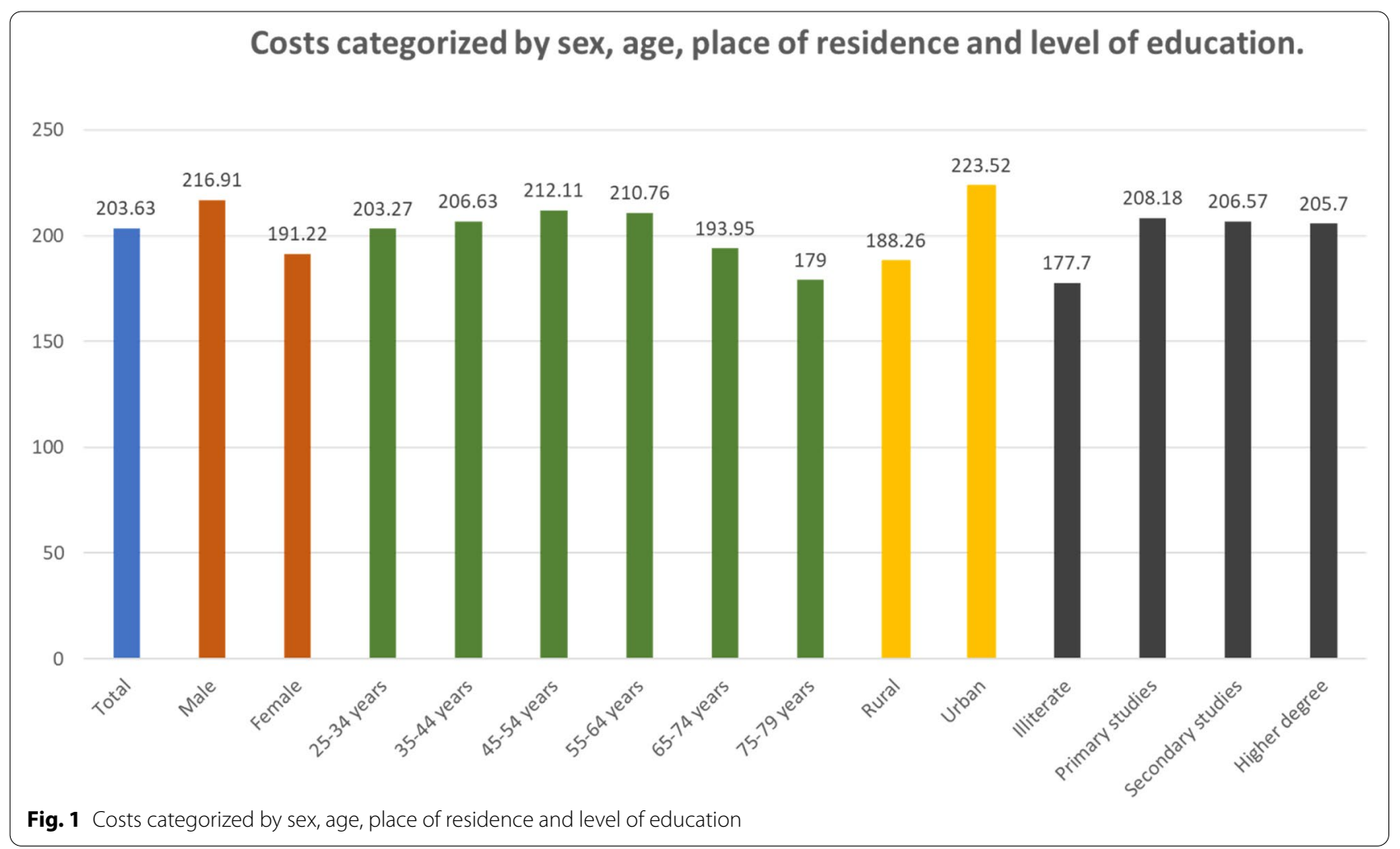

Table 3 Monthly cost according to the indicator of adherence to the Mediterranean Diet of Panagiotakos

\begin{tabular}{lllll}
\hline & & Low adherence & $\begin{array}{l}\text { Medium } \\
\text { adherence }\end{array}$ & High adherence \\
\hline N & & 335 & 828 & 1670 \\
& $\%$ & 11,82 & 29,23 & 59,95 \\
Median & & 153,56 & 170,54 & 229,38 \\
Percentiles & 25 & 117,25 & 138,46 & 184,35 \\
& 75 & 204,19 & 213,30 & 295,64 \\
Pearson's cor- & & 0,39 & & \\
relation & & & & \\
Kruskal-Wallis' & & 0,001 & & \\
test & & & & \\
\hline
\end{tabular}

Own elaboration with data from HERMEX study

concluded that the expenditure of individuals with good adherence to the MD was higher $(0.64 €$ more for each $1000 \mathrm{kcal}$ ) as compared to those with the same level of adherence following the "Western food pattern".

According to a study of 2014 by the Harvard School of Public Health [28], which analysed consumer choices in recent decades, differences in the choice of food between individuals belonging to extreme income deciles are becoming more evident every year. The economic crisis contributed towards the increasingly unhealthy eating habits of the population with lower economic resources. This study also revealed significant differences according to educational attainment. However, this variable was not relevant in our research.

The Moli-Sani study [29], analyzed the relationship between adherence to healthy diet and economic characteristics of the adult population living in Italian region of Molise. The higher income groups showed a positive difference of two points in adherence to the MD, which was also associated with a $15 \%$ reduction of the risk of CVD.

So far, the sex perspective has not been considered in most studies that have addressed the cost of diet, especially in the case of adherence to the MD. In our study, the MFC of women's diets is $11.84 \%$ lower than men's. Underlying reasons may involve lower income level of women [30, 31], differences in dietary patterns, as well as a better use of resources due to the socio-cultural pattern that has determined deeper involvement in household chores.

Neither have we found any information on lower expenses in rural areas; in our opinion this may be due to the lower cost of foods in this milieu. 
Table 4 Monthly cost and adherence rates for various income indicators

\begin{tabular}{|c|c|c|c|c|c|}
\hline & $\begin{array}{l}\text { Median cost } \\
(€ / \text { month })\end{array}$ & $\begin{array}{l}\text { MW* } \\
2019\end{array}$ & $\begin{array}{l}\text { IPREM }^{* *} \\
2019\end{array}$ & $\begin{array}{l}\text { MVI *** } \\
2020\end{array}$ & $\begin{array}{l}\text { nCP **** } \\
2019\end{array}$ \\
\hline Income index (€/month) & & 900 & 537,84 & 462 & 392 \\
\hline In \% respect to the average income & 203,36 & $22,60 \%$ & $37,81 \%$ & $44,02 \%$ & $51,88 \%$ \\
\hline \multicolumn{6}{|l|}{$P A l^{* * * *}$} \\
\hline Low adherence & 153,56 & $17,06 \%$ & $28,55 \%$ & $33,24 \%$ & $39,17 \%$ \\
\hline Medium adherence & 170,54 & $18,95 \%$ & $31,71 \%$ & $36,91 \%$ & $43,51 \%$ \\
\hline \multirow[t]{2}{*}{ High adherence } & 229,38 & $25,49 \%$ & $42,65 \%$ & $49,65 \%$ & $58,52 \%$ \\
\hline & $\begin{array}{l}\text { Median cost } \\
(€ / \text { month) }\end{array}$ & Spain & Extremadura & Badajoz & $\begin{array}{l}\text { Municipalities of Vegas } \\
\text { Altas, La Siberia and La } \\
\text { Serena }\end{array}$ \\
\hline Average disposable income (€/year) & & 22.634 & 17.361 & 17.439 & 16.288 \\
\hline Average disposable income (€/month) & & 1886,17 & 1446,75 & 1453,25 & 1357,30 \\
\hline In \% respect to the average income & 203,36 & $10,78 \%$ & $14,06 \%$ & $13,99 \%$ & $14,98 \%$ \\
\hline \multicolumn{6}{|l|}{$P A l^{* * * * *}$} \\
\hline Low adherence & 153,56 & $8,14 \%$ & $10,61 \%$ & $10,57 \%$ & $11,31 \%$ \\
\hline Medium adherence & 170,54 & $9,04 \%$ & $11,79 \%$ & $11,74 \%$ & $12,56 \%$ \\
\hline High adherence & 229,38 & $12,16 \%$ & $15,85 \%$ & $15,78 \%$ & $16,90 \%$ \\
\hline
\end{tabular}

* MW: Minimum Wage

** IPREM: Public Indicator of Multiple Effects Income

*** MVI: Minimum Living Income (single-person household)

**** nCP: Non-Contributory Pension (one-person household)

***** PAl: Panagiotakos Adherence Index

Own elaboration based on data from the Statistical System of Extremadura - Citizen Portal (gobex.es)

Finally, the MFC is $15.61 \%$ lower in the $75-59$ age cohort than in the 45-54 age cohort. There is evidence that older cohorts stick more closely to Mediterranean dietary pattern in their meals [32].

A closer look should be taken at all this in suitably designed studies.

\section{Choices in the management of public health}

From the perspective of public health policies, our results strengthen the importance of strategies towards the improvement of diet quality, especially, focusing on the lowest socioeconomic groups [33]. These actions should be implemented in two complementary fields. Firstly, consumers should be educated on the nutritional value and cost of food. In this sense the studies of Drewnowski et al. [34] and Goulet et al. [35] confirm the fact that Mediterranean-style foods can be obtained at all price ranges whether in grams or in calories. The only condition for keeping the Mediterranean diet pattern at a reasonable price is to include more cereals, vegetables, and seasonal fruit. Therefore, emphasis should be placed on communication strategies that disseminate how healthy foods can be selectively purchased within products of different economic value at a lower total cost.

Secondly, there is a controverted debate about the reduction of indirect taxes (VAT) on healthy (e.g. MD) [36, 37], and/or the increase of taxes on unhealthy food (e.g. sugary drinks) [38-40] is being discussed. In this sense, Andreyeva et al [41], highlight the difficulty to carry out a rigorous analysis because changes in the economic scenario (i.e., increase of VAT) could alter price and cross demand elasticities.

Future research should focus on the prediction of the impact of these fiscal policies and in this sense, interdisciplinary work is essential in order to reach a consensus.

\section{Limitations}

The main limitations faced by this work are twofold. On the one hand, the fact of using consumption data corresponding to the period 2007-2009 and price data for 2019. Secondly, the possibility of extrapolating the results obtained for Extremadura to the national level.

With regard to the first limitation, table A3 in the Appendix shows the average annual cumulative rate of the Consumer Price Index (CPI) for food, non-alcoholic beverages and alcoholic beverages, as well as the average 
disposable income in the period 2008-2019. It can be seen that the cumulative average annual growth rate in Badajoz is slightly higher than the growth rate of the aforementioned CPI components. Therefore, there has been no loss of purchasing power in these components over the period considered, and the dietary data collected in 2007-2009 could be considered representative of the diet in 2019.

Regarding the second limitation, the extrapolation of the average cost of the MD in the municipalities of Vegas Alta, La Serena and La Siberia to the country as a whole presents some restrictions. Firstly, the average disposable income in Spain was 37.67\% (29.79\%) higher than in Badajoz in 2008 (2019).

Secondly, the percentage of household expenditure devoted to food is higher in Badajoz (39.20 percentage points in 2008 and 42.27 percentage points in 2019) (see table A4 in the Appendix). However, for the whole country and for Badajoz, there has been a decrease in the share of food in the shopping basket (-13.96 points for Spain and -17.03 points for Badajoz). On the other hand, the average annual accumulated growth rate of average disposable income has been higher in Badajoz (1.376\% compared to $0.834 \%)$ and also higher than the growth of the three groups of goods considered (food, nonalcoholic beverages and alcoholic beverages) (see Table A4 in the Appendix). These data suggest a process of convergence of average disposable income in Badajoz to the Spanish average income and also a greater similarity with average consumption patterns at the national level.

\section{Conclusions}

The MFC in a low-income region was positively correlated with the level of adherence to the MD and is similar to other Spanish regions with higher per capita income, which relates higher expenditure to achieve equality of adherence to the MD.

With regard to the measures traditionally proposed (taxes or subsidies), it should be considered an implementation of these, at regional level (in the poorest regions, where access to MD is less affordable in relative terms) for example in the form of income supplements for the lowest levels of income. In any case, further research on the costeffectiveness of these measures and coordination in fiscal and social policies would be necessary.

The sex deserves a more in-depth analysis.

Knowledge and handling of this information by healthcare personnel should be useful if they consider in their dietary indications the economic factors having a positive or negative effect on their compliance.

\section{List of abbreviations}

CVD: Cardiovascular disease; MD: Mediterranean Diet; PAI: Panagiotakos Adherence Index; MFC: Monthly Food Cost.

\section{Supplementary Information}

The online version contains supplementary material available at https://doi. org/10.1186/s12889-021-12433-w.

Additional file 1 : Table A1. Amounts consumed depending on the frequency of consumption. Table A2. Descriptive statistics for the prices of all product categories. Table A3. Comparison of evolution of food and beverages prices and average disposable income in the period 2008-2019. Table A4. Comparison of the weight that food and beverages represent in the shopping basket.

\section{Acknowledgements}

Not applicable.

\section{Authors' contributions}

AR: Conception and design of the work; interpretation of data; analysis of the results; drafting and revision of the manuscript; final approval of version to be published; accountability for all aspects of the work. CVP: Conception and design of the work; interpretation of data; analysis of the results; drafting and revision of the manuscript; final approval of version to be published. MFA: analysis of the results; drafting and revision of the manuscript; final approval of version to be published. LYR: analysis of the results; drafting of the manuscript; final approval of version to be published. MHG: analysis of the results; drafting of the manuscript; final approval of version to be published. FJFG: analysis of the results; drafting of the manuscript; final approval of version to be published. FJFR: Conception and design of the work; interpretation of data; analysis of the results; revision of the manuscript; final approval of version to be published; accountability for all aspects of the work. DFB: Conception and design of the work; interpretation of data; analysis of the results; drafting and revision of the manuscript; final approval of version to be published; accountability for all aspects of the work.

\section{Funding}

The present work has been financed by: Carlos III Health Institute [PI071218 National Plan for Scientific Research 2004-07 (Funded the medical staff for 3 years and material for the extraction of samples and indirect costs of the project) EMER 07/046 Grants for emerging research groups (Funding of personnel: nurse, doctor and technician) - INT 07/289 Grants for intensification of personal care research (Funded a researcher for 6 months)], Fundesalud [Integral Plan Grant for Cardiovascular Diseases in Extremadura (Funded a lab technician during patient enrolment)] and Junta de Extremadura and European Union (ERDF) [GR18076 Aid to Research Groups 2018 (Funded a research support technician)].

\section{Availability of data and materials}

Data available: Rubini, Alessia (2021): HERMEX BMC.sav. figshare. Dataset. https://doi.org/10.6084/m9.figshare.17104760.v1.

\section{Declarations}

\section{Ethics approval and consent to participate}

The study was approved by the Ethics Committee of the University Hospital of Badajoz, all participants in the study have signed a consent to participate.

\section{Consent for publication}

Not applicable.

\section{Competing interests}

The author(s) declare(s) that they have no competing interests

\section{Author details}

${ }^{1}$ Research Unit of Don Benito-Villanueva de la Serena Health Area, Calle Sierra Nevada, 10, 06700 Villanueva de la Serena, Spain. ${ }^{2}$ University institute for Biosanitary Research of Extremadura (INUBE), Badajoz, Spain. ${ }^{3}$ Faculty of Economics and Business, University of Murcia, Murcia, Spain. ${ }^{4}$ Department of Physiology, University of Granada, Granada, Spain. ${ }^{5}$ Finance and Accounting, University of Extremadura, Badajoz, Spain. ${ }^{6}$ Medical Manager of the General Directorate of Health Assistance, Extremadura Health Service, Mérida, Spain. 
Received: 27 May 2021 Accepted: 17 December 2021

Published online: 10 January 2022

\section{References}

1. Estruch R, Ros E, Salas-Salvadó J, et al. Primary prevention of cardiovascular disease with a Mediterranean Diet. N Engl J Med. 2013;368(14):1279-90.

2. Salas-Salvadó J, Sánchez M. El gran ensayo de campo nutricional. Predimed. Nutr Clín Med. 2017;11(1):1-8.

3. Velasco Rami JA. Importancia de la dieta mediterránea en una alimentación cardiosaludable. Educación Alimentaria. 1994.

4. Rodríguez Roca GC, López Abuín JM. La dieta mediterránea: una forma de nutrición saludable. Semergen. 2003;29(6):301-7.

5. Bernárdez Míguez M, Castro Sobrino L, Collins Green A. De la montaña Miguélez J. Variaciones en la dieta de universitarios gallegos (campus de Ourense) con relación al patrón cardioprotector de la dieta mediterránea. Nutrición Hospitalaria. 2013;28(6):2099-106.

6. Bloomfield HE, Kane R, Koeller E, Greer N, MacDonald R, Wilt T. Benefits and harms of the Mediterranean Diet compared to other diets [Internet]. Washington (DC): Department of Veterans Affairs (US); 2015 Nov.

7. Saulle R, La Torre G. The Mediterranean diet, recognized by UNESCO as a cultural heritage of humanity. Ital J Public Health. 2010;7:4114-5.

8. Kearney M, Kearney J, Dunne A, et al. Socio-demographic determinants of perceived influences on food choice in a nationally representative sample of Irish adults. Public Health Nutr. 2000;3:219-26.

9. Bowman S. A methodology to price food consumed: development of a food price database. Fam Econ Nutr Rev. 1997;10:26-33.

10. Mhurchu CN. Food costs and healthful diets: the need for solutionoriented research and policies. Am. Jr Clin. Nutr. 2010;92:1007-8.

11. Rao M, Afshin A, Singh G, et al. Do healthier foods and diet patterns cost more than less healthy options? A systematic review and meta-analysis. BMJ Open. 2013;3:e004277.

12. Fernández Bermejo F, et al. Un indicador de nivel socioeocómico para Extremadura. Trabajo vinculado al proyecto Atlas Sociosanitario de Extremadura. Junta de Extremadura. Consejería de Sanidad y Políticas Sociales. 2017:15-7.

13. Rehm CD, Monsivais P, Drewnowski A. Relation between diet cost and Healthy Eating Index 2010 scores among adults in the United States 2007-2010. Preve Med. 2015;73:70-5.

14. Darmon N, Drewnowski A. Contribution of food prices and diet cost to socioeconomic disparities in diet quality and health: a systematic review and analysis. Nutr Rev. 2015;73:643-60.

15. López CN, Martínez-González MA, Sánchez-Villegas A, et al. Costs of Mediterranean and western dietary patterns in a Spanish cohort and their relationship with prospective weight change. J Epidemiol Community Health. 2009;63:920-7.

16. Darmon N, Ferguson E, Briend A. Do economic constraints encourage the selection of energy dense diet? Appetite. 2003;41(3):315-22.

17. Drewnowski A, Darmon N. Food Choices and Diet Costs: an economic Analysis. J. Nutr. 2005;135(4):900-4.

18. Schröder H, Marrugat J, Covas MI. High monetary cots of dietary patterns associated with lower body mass index: a population-based study. Int J Obes (Lond). 2006;30:1574-9.

19. Instituto Nacional de Estadística. Causa básica de defunción. Comunidades y Ciudades Autónomas. Año 2018. https://www.ine.es/dynt3/ inebase/es/index.htm?padre $=6177 \& \mathrm{capsel}=6179$ (Nov 2021).

20. Instituto Nacional de Estadística. Encuesta de Condiciones de Vida (ECV), Comunidades y Ciudades Autónomas, Renta anual neta media por persona y por unidad de consumo 2018. https://www.ine.es/jaxiT3/Datos. htm?t=9947\#!tabs-grafico (Jan 2021).

21. Félix-Redondo FJ, Fernández-Bergés D, Pérez JF, et al. Prevalencia, detección, tratamiento y grado de control de los factores de riesgo cardiovascular en la población de Extremadura. Estudio HERMEX. Aten Primaria. 2011;43(8):426-34.

22. Schröder H, Covas MI, Marrugat J, et al. Use of a three-day estimated food record, a 72-hour recall and a food-frequency questionnaire for dietary assessment in a Mediterranean Spanish population. Clin Nutr. 2001;20(5):429-37.
23. Panagiotakos DB, Pitsavos C, Stefanadis C. Dietary patterns: A Mediterranean diet score and its relation to clinical and biological markers of cardiovascular disease risk. Nutr Metab Cardiovasc Dis. 2006;16(8):559-68.

24. Zaragoza-Marí A, Cabañero-Martínez MJ, Hurtado-Sánchez JA, et al. Evaluation of Mediterranean diet adherence scores: a systematic review. BMJ Open. 2018;8:e019033.

25. Sistema Estadístico de Extremadura. https://ciudadano.gobex.es/web/ ieex/sistema-estadistico-de-extremadura . (Jan 2021)

26. Fresán U, Martínez-González M, Sabaté J, Bes-Rastrollo M. Global sustainability (health, environment and monetary costs) of three dietary patterns: results from a Spanish cohort (the SUN project). BMJ Open. 2019;9(2):e021541.

27. López CN, Martinez-Gonzalez MA, Sanchéz-Villegas A, Alonso A, Pimenta AM, Bes-Rastrollo M. Costs of Mediterranean and western dietary patterns in a Spanish cohort and their relationship with prospective weight change. J Epidemiol Community Health. 2009;63(11):920-7.

28. Wang DD, Leung CW, LiY, et al. Trends in dietary quality among adults in the United States, 1999 through 2010. JAMA Intern Med. 2014;174(10):1587-95.

29. Bonaccio M, Di Castelnuovo A. Pounis $\mathrm{G}$ et al on behalf of the Molisani Study Investigators. High adherence to the Mediterranean diet is associated with cardiovascular protection in higher but not in lower socioeconomic groups: prospective findings from the Moli-sani study. Int J of Epidemiol. 2017:46(5):1478-87.

30. Blau F, Kahn L. The gender wage gap: extent, trends and explanations. J Econ Lit. 2017;55(3):789-865.

31. Magnusson C. Why is there a gender wage gap according to occupational prestige? An analysis of the gender wage gap by occupational prestige and family obligations in Sweden. Acta Sociologica. 2010;53(2):99-117.

32. Buscemi S. What are the determinants of adherence to the Mediterranean diet? Int J Food Sci Nutr. 2021;72(2):143-4.

33. Powell LM, Chriqui JF, Khan T, et al. Assessing the potential effectiveness of food and beverage taxes and subsidies for improving public health: a systematic review of prices, demand and body weight outcomes. Obes Rev. 2013;14(2):110-28.

34. Drewnowski A, Eichelsdoerfer P. The Mediterranean diet: does it have to cost more? Public Health Nutr. 2009;12(9A):1621-8.

35. Goulet J, Lamarche B, Lemieux S. A nutritional intervention promoting a Mediterranean food pattern does not affect total daily dietary cost in North American women in free-living conditions. J Nutr. 2008;138:54-9.

36. Dallongeville J, Dauchet L, de Mouzon O, Réquillart V, Soler LG. Increasing fruit and vegetable consumption: a cost-effectiveness analysis of public policies. Eur J Public Health. 2011;21(1):69-73.

37. Gustavsen GW, Rickertsen K. Adjusting VAT rates to promote healthier diets in Norway: a censored quantile regression approach. Food Policy. 2013;42:88-95.

38. Franck C, Grandi SM, Eisenberg M. Taxing junk food to counter obesity. American J Public Health. 2013;103:1949-53.

39. Encarnação R, Lloyd-Williams F, Bromley H, Capewell S. Obesity prevention strategies: could food or soda taxes improve health? J R Coll Physicians Edinb. 2016;46:32-8.

40. Pomeranz J, Wilde P, Huang Y, Micha R, Mozaffarian D. Legal and administrative feasibility of a federal junk food and sugar-sweetened beverage tax to improve diet. Ame J Public Health. 2018;108:203-9.

41. Andreyeva T, Long MW, Brownel KD. The impact of food prices on consumption: A systematic review of research on the price elasticity of demand for food. Am J Public Health. 2010;100(2):216-22.

\section{Publisher's Note}

Springer Nature remains neutral with regard to jurisdictional claims in published maps and institutional affiliations. 